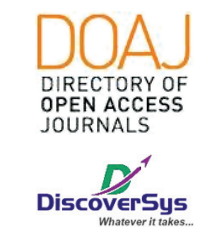

Published by DiscoverSys

\section{Foto polos abdomen megaureter kongenital pada kecurigaan cystoma ovari maligna: Laporan kasus}

\author{
Rein Matondang, ${ }^{1 *}$ Ni Nyoman Margiani ${ }^{2}$
}

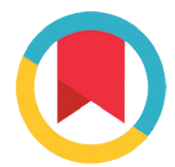

CrossMark

\section{ABSTRACT}

Background: Megaureter defined as dilated ureter with or without dilatation of the renal pelvis and calyces. Megaureter is a common diagnosis in children, representing $23 \%$ of children with urinary tract obstruction. The diagnosis is more common in boys than girls, and more often is on the left side.

Case description: A 17-year-old female was referred with a suspicion of malignant ovarian cystoma. On examination, the abdomen was distended. Plain radiograph of the abdomen revealed ground glass appearance in abdominal-pelvic cavity suspected of abdominal mass. An ultrasound of the abdomen revealed moderate right hydronephrosis and severe left hydronephrosis. Abdominal
CT Scan with contrast demonstrated grade II right hydronephrosis with proximal hydroureter and grade III-IV left hydronephrosis, no solid mass in abdomen. Gynecologyst suspected this patient with left ovarian cystic mass. During the operation, evaluation to obtained ovarian cystic mass was done, yet no mass was obtained. They found a left mega ureter from proximal to distal suspected of a congenital giant mega ureter, followed by left nefrectomy and ureterectomy.

Conclusion: A ground glass appearance in plain x-ray may mimicking as hydronephrosis or gynecological mass, particularly in young female patients with suspicion of abdominal mass.

Key words: plain abdominal, abdominal mass, congenital mega ureter

Cite This Article: Matondang, R., Margiani, N.N. 2020. Foto polos abdomen megaureter kongenital pada kecurigaan cystoma ovari maligna: Laporan kasus. Intisari Sains Medis 11(1): 373-377. D0I: 10.15562/ism.v11i1.722

ABSTRAK

Latar belakang: Megaureter didefinisikan sebagai ureter yang melebar dengan atau tanpa dilatasi pelvis renalis dan calix ginjal. Megaureter adalah diagnosis yang umum pada anak-anak, mewakili 23\% diagnosis pada anak-anak dengan obstruksi saluran kemih. Diagnosis ini lebih sering terjadi pada anak laki-laki daripada anak perempuan, dan lebih sering di sisi kiri.

Deskripsi kasus: Seorang wanita berusia 17 tahun dirujuk dengan kecurigaan sistoma ovarium maligna. Pada pemeriksaan, perut tampak distensi. Foto polos abdomen menunjukkan ground glass appearence di rongga perut-panggul yang diduga massa abdomen.

'Program Studi Pendidikan Dokter Spesialis Radiologi, Fakultas Kedokteran Universitas Udayana/ RSUP Sanglah Denpasar, Bali, Indonesia

Departemen/ KSM Radiologi, Fakultas Kedokteran Universitas Udayana/RSUP Sanglah, Denpasar, Bali, Indonesia

*Korespondensi: Rein Matondang, Program Studi Pendidikan Dokter Spesialis Radiologi, Fakultas Kedokteran Universitas Udayana/ RSUP Sanglah Denpasar, Bali, Indonesia

repdaku@gmail.com

Diterima: 26-02-2020

Disetujui: 27-03-2020

Diterbitkan: 01-04-2020

Ultrasonografi abdomen menunjukkan hidronefrosis kanan sedang

\section{PENDAHULUAN}

Megaureter didefinisikan sebagai pelebaran ureter dengan atau tanpa dilatasi pelvis renalis dan kaliks ginjal. Diameter normal ureter pada anak-anak biasanya adalah $5 \mathrm{~mm}$, dan jarang melebihi ukuran ini. Dalam praktisnya, ureter dengan diameter $7 \mathrm{~mm}$ atau lebih harus dipertimbangkan sebagai megaureter. Megaureter dapat dikategorikan sebagai primer atau sekunder, refluks atau nonrefluks, obstruksi atau non-obstruksi. ${ }^{1}$ dan hidronefrosis kiri berat. CT-Scan abdomen dengan kontras menunjukkan hidronefrosis kanan derajat II dengan hidroureter proksimal dan hidronefrosis kiri derajat III-IV, tidak tampak massa padat di perut. Dicurigai suatu massa kistik ovarium kiri. Selama operasi, dilakukan evaluasi untuk menemukan massa kistik ovarium, namun tidak didapatkan. Ditemukan megaureter kiri dari proksimal ke distal yang diduga sebagai giant megaureter kongenital, dilanjutkan nefrektomi kiri dan ureterektomi.

Kesimpulan: Suatu gambaran ground glass appearance pada foto polos dapat menyerupai hidronefrosis atau masa ginekologi terutama pada wanita muda yang dicurigai massa abdomen.

Kata kunci: foto polos abdominal, massa abdomen, mega ureter kongenital

Cite Pasal Ini: Matondang, R., Margiani, N.N. 2020. Foto polos abdomen megaureter kongenital pada kecurigaan cystoma ovari maligna: Laporan kasus. Intisari Sains Medis 11(1): 373-377. D0l: 10.15562/ism.v11i1.722
Megaureter adalah diagnosis paling sering pada anak-anak, sekitar $23 \%$ dari anak-anak dengan obstruksi saluran kemih. Kasus megaureter paling sering terjadi pada laki-laki daripada perempuan, dan lebih sering mengenai sisi kiri. Sekitar 25\% kasus megaureter terjadi bilateral, dan ginjal kontralateral mengalami displasia pada 10-15\% kasus. Tidak ada penjelasan apakah megaureter merupakan kelainan genetic atau tidak. ${ }^{2}$ 
Pada megaureter gambaran histologis yang ditemukan adalah peningkatan jumlah jaringan ikat pada ureter abnormal. Sebuah studi menunjukkan bahwa rasio kolagen terhadap otot polos dalam ureter normal adalah 0,52 , sementara itu rasio pada megaureter obstruksi adalah sebesar 0,78 dan rasio pada megaureter refluks adalah sebesar 1,99 . Studi lain menunjukkan bukti pada megaureter, sel otot polos dalam ureter menghasilkan peningkatan jumlah kolagen abnormal. Otot-otot di segmen ureter ini juga telah terbukti merespons secara tidak normal untuk neurotransmiter, menunjukkan anomali sel-sel ini. ${ }^{3}$

Banyak kasus megaureter yang tidak pernah menimbulkan gejala. Sebagian besar kasus megaureter pertama kali terdeteksi dengan USG prenatal dan kemudian terdiagnosis setelah lahir. Beberapa kasus muncul gejala selama masa kanakkanak dengan keluhan nyeri perut, hematuria, dan atau infeksi saluran kemih. ${ }^{2}$ Ultrasonografi adalah pemeriksaan yang sederhana, aman, dan tidak nyeri yang dapat memberikan informasi penting mengenai ukuran ginjal, ketebalan parenkim, dilatasi uretra dan pelvis ginjal, ketebalan dinding kandung kemih, dan obstruksi uretra. ${ }^{4}$ Megaureter sering ditemukan secara kebetulan di kemudian

\section{Tabel 1 Hasil laboratorium pasien}

\begin{tabular}{lc}
\hline Laboratorium & Hasil \\
\hline Hemoglobin & $11,17 \mathrm{~g} / \mathrm{dL}$ \\
Leukosit & $22,50 \times 10^{3} / \mu \mathrm{L}$ \\
Trombosit & $337 \times 10^{3} / \mu \mathrm{L}$ \\
Hematokrit & $38 \%$ \\
BUN & $12,00 \mathrm{mg} / \mathrm{dL}$ \\
Kreatinin & $0,81 \mathrm{mg} / \mathrm{dL}$ \\
CEA 125 & $17,5($ normal: $<35)$ \\
Urinalisa & \\
- Berat Jenis & 1,013 \\
- Kekeruhan & Keruh $(+++)$ \\
- pH & 6,50 \\
- Leukosit & Pos $(++++)$ \\
- Nitrit & Pos $(++)$ \\
- Protein & Pos $(+)$ \\
- Keton & Normal \\
- Darah & Negatif \\
- Urobilinogen & Pos $(++)$ \\
\hline
\end{tabular}

BUN: Blood urea nitrogen hari pada saat pemeriksaan pencitraan, dan jarang menyebabkan insufisiensi ginjal. ${ }^{2}$

\section{LAPORAN KASUS}

Seorang wanita 17 tahun dirujuk dari rumah sakit lain dengan kecurigaan sistoma ovarium maligna. Pasien belum pernah menikah dan terdapat penurunan berat badan sekitar $10 \mathrm{~kg}$ selama tiga bulan terakhir. Tidak ada riwayat perdarahan vagina atau keputihan. Menarche pada usia 11 tahun. Pada pemeriksaan, perut tampak distensi. Hasil pemeriksaan laboratorium dilihat pada tabel 1 .

Pada pemeriksaan imaging, foto polos abdomen menunjukkan gambaran ground glass appearance dirongga perut-panggul yang diduga massa abdominal (Gambar 1). Sedangkan pada ultrasonografi abdomen menunjukkan hidronefrosis kanan sedang dan hidronefrosis kiri berat (Gambar 2). Pemeriksaan CT-Scan abdomen dengan kontras menunjukkan hidronefrosis kanan derajat II dengan hidroureter proksimal dan hidronefrosis kiri derajat III-IV, tidak ada massa padat pada abdomen.

Pasien dicurigai dengan massa kistik ovarium kiri. Pasien kemudian dilakukan operasi laparotomi eksplorasi. Dari hasil operasi ditemukan adanya megaureter kiri dari proksimal ke distal yang diduga sebagai giant megaureter kongenital, disertai nefrektomi kiri dan ureterektomi (Gambar 4).

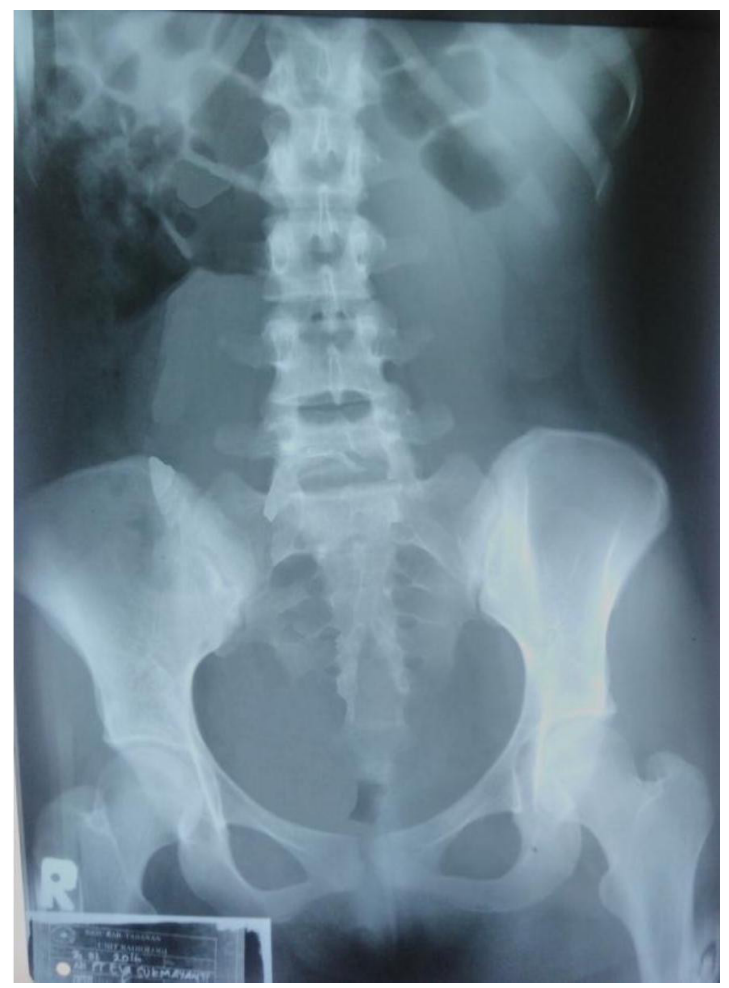

Gambar 1 Foto polos abdomen 

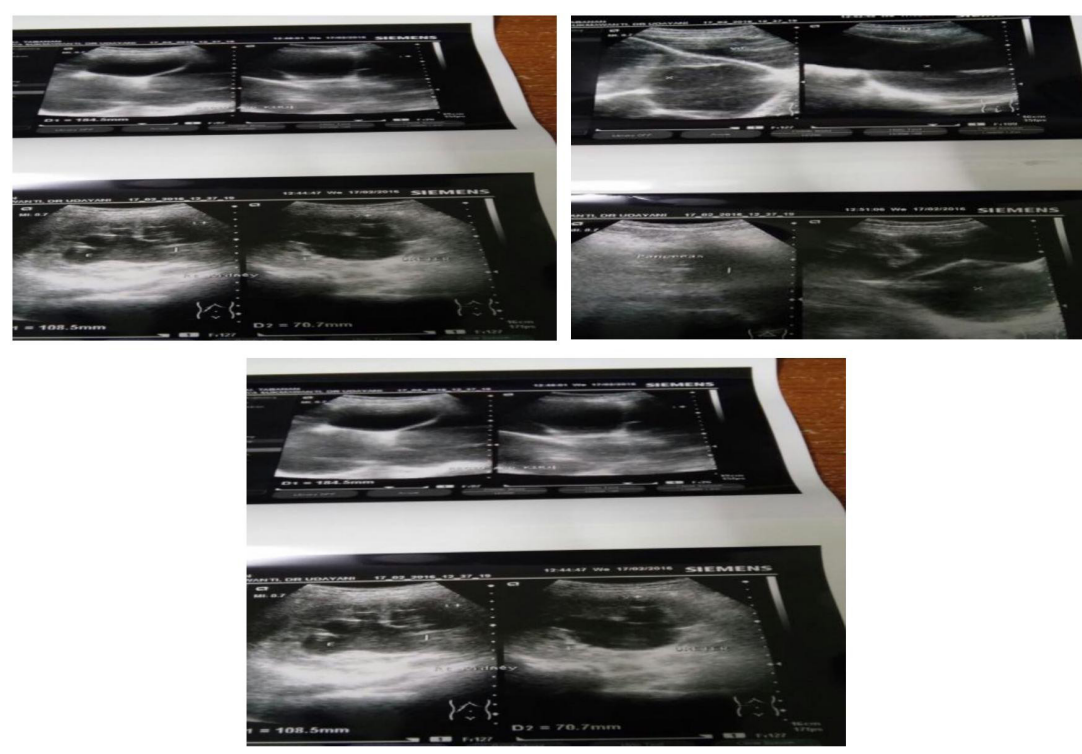

Gambar 2 Renal Ultrasonografi
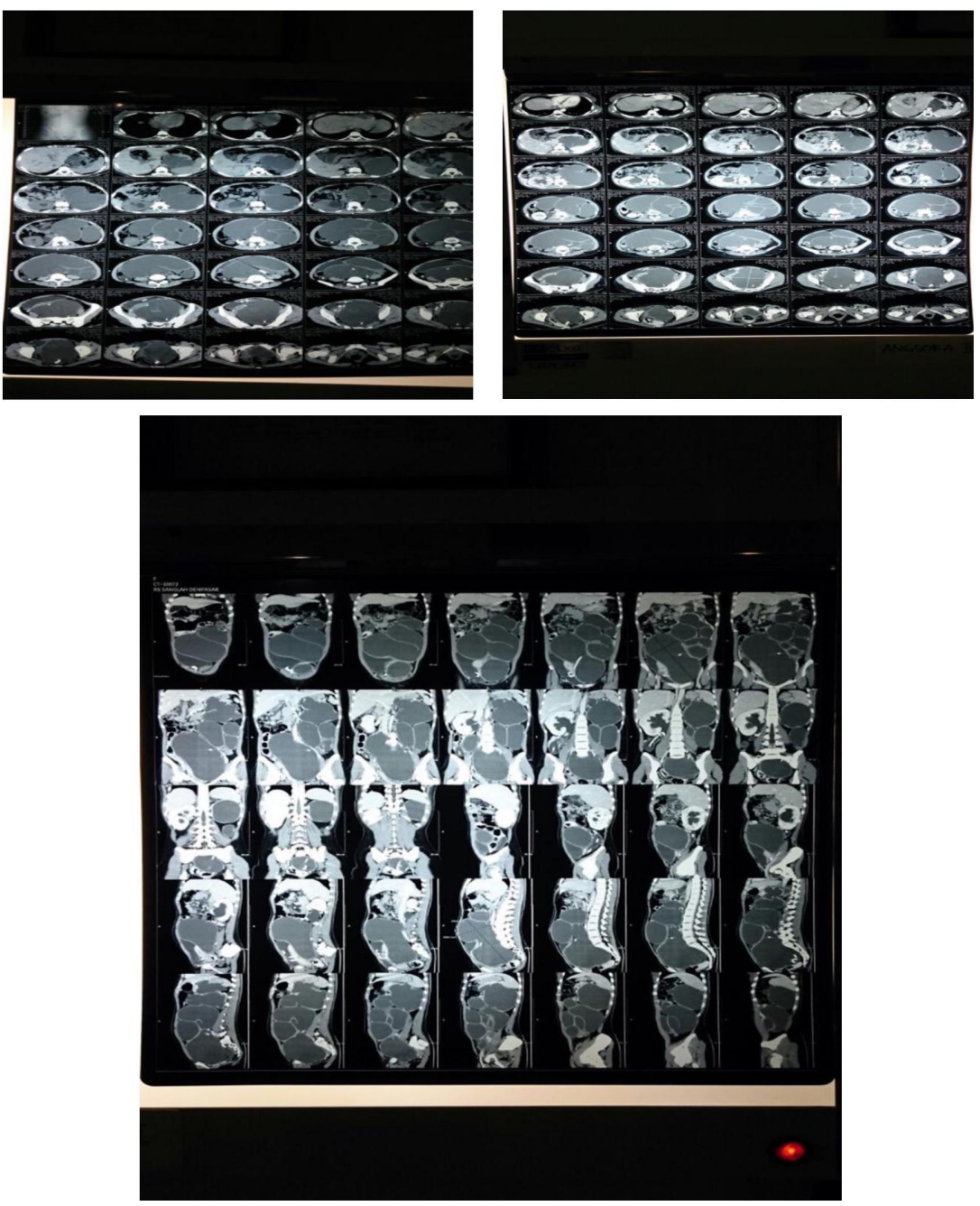

Gambar 3 Gambaran CT-Scan Abdomen pasien
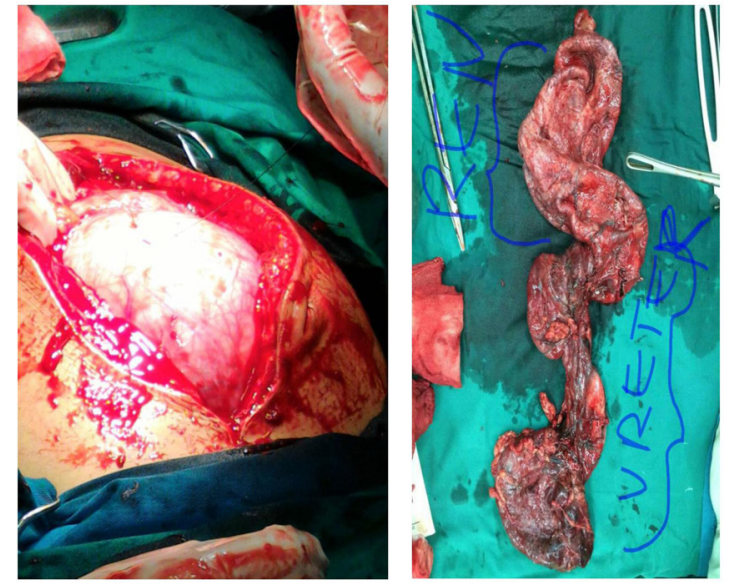

Gambar 4 Operasi laparotomi eksplorasi didapatkan megaureter kiri

\section{PEMBAHASAN}

Megaureter adalah diagnosis umum pada anakanak, mewakili 23\% diagnosis pada anak-anak dengan obstruksi saluran kemih. Dalam kasus ini kami menemukan megaureter pada remaja yang dicurigai massa abdomen. Pasien belum pernah menikah. Foto polos abdoomen tidak dapat menunjukkan megaureter dengan jelas. Dari foto polos hanya menunjukkan ground glass appearance terlihat di rongga perut hingga panggul yang sulit dibedakan dari massa intra-abdominal. Ultrasonografi abdomen dan CT-scan dengan kontras menunjukkan hidronefrosis dan hidroureter kiri tanpa massa padat dirongga abdomen. Pemeriksaan voiding cystourethrography (VCUG) dan Magnetic Resonance (MR) urologi tidak dilakukan. Pasien dicurigai dengan massa kistik ovarium kiri dan memutuskan melakukan laparotomi eksplorasi. Selama operasi dilakukan evaluasi dan tidak didadpatkan massa kistik ovarium. Namun pada pasien ditemukan megaureter kiri dari proksimal ke distal yang diduga sebagai giant mega ureter kongenital, dilanjutkan nefrektomi kiri dan ureterektomi.

Megaureter adalah penyakit sporadik atau familial, dimana laki-laki lebih sering terkena daripada perempuan dan penyebab tersering adalah obstruksi kandung kemih. Dalam megaureter obstruktif primer, obstruksi berada pada atau tepat di atas Uretero-Vesical Junction (UVJ) dan paling sering merupakan hasil dari segmen juxtavesical adinamik ureter yang gagal untuk mengalirkan urin. Megaureter dapat terjadi bilateral pada 20\% kasus dengan rasio laki-laki dan perempuan sebanyak 4: 1,4 dimana sisi kiri lebih sering terkena. Di sisi lain, megaureter obstruktif sekunder merupakan 
hasil dari obstruksi ureter fungsional yang berkaitan dengan tekanan kandung kemih yang meningkat yang menghambat pengosongan ureter. ${ }^{1} \mathrm{Hal}$ ini dapat menyebabkan kerusakan ginjal melalui mekanisme, yang didalamnya mencakup proses inflamasi. ${ }^{5}$

Megaureter refluks primer terjadi karena kegagalan mekanisme anti-refluks di UVJ, sementara megaureter refluks sekunder terjadi terhadap posterior urethral valve (PUV) dan neurogenic bladder (NGB) ketika tekanan kandung kemih meningkat karena inkompetensi UVJ. Megaureter berkaitan dengan agenesis ginjal unilateral, sistem dupleks komplit atau inkomplit, ginjal ektopik, ginjal kistik kontralateral dan displastik, ginjal horseshoe, atau penyakit Hirschsprung. ${ }^{6}$

Studi pencitraan seperti ultrasound, Voiding cysto-urethrogram (VCUG), renegrafi nuklir diuretik, Intravenous Pyelogram (IVP), peningkatan kontras CT, dan MRI dapat digunakan dalam mendiagnosis kasus megaureter. Ultrasound abdomen merupakan metode dasar untuk mengetahui morfologi ginjal dan ureter. Urografi intravenous merupakan metode diagnosis mayor yang dapat memperlihatkan ureter dan pelvis ginjal yang terdilatasi, begitu pula dengan morfologi ureter dan memperkirakan fungsi ginjal. Magnetic resonance urography (MRU) dikombinasikan dengan urografi dapat dengan jelas memperlihatkan adanya ureter dan pelvis ginjal yang mengalami dilatasi, begitu pula dengan lokasi segmen yang menyempit. Oleh karena itu, MRU dapat menjadi pilihan yang bagus untuk pasien bayi. ${ }^{7}$

Terapi bedah diindikasikan untuk megaureter sekunder hingga obstruksi atau refluks vesikoueretrik berat, dan biasanya ditangani dengan reimplantasi ureter. Nefroureterektomi dapat diindikasikan pada kerusakan fungsi ginjal berat. ${ }^{1}$ Terapi awal untuk megaureter walaupun dilatasi berat dan refluks derajat berat diterapi dengan antibiotika profilaksis dan observasi. Pembedahan hanya dipertimbangkan untuk refluks derajat berat yang persisten pada anak dengan usia yang lebih tua (khususnya dengan pyelonephritis rekuren) dan pada bayi yang gagal dengan terapi medikamentosa. Kejadian komplikasi uteroneosistostomi tinggi ketika dilakukan pada anak di bawah usia setahun. $^{2}$

Refluks sekunder harus diterapi dengan mengatasi penyebab peningkatan tekanan intravesika yang menyebabkan refluks, misalnya pada anakanak dengan katup uretra posterior dan refluks, seringkali ablasi katup dan manajemen kandung kemih yang tepat akan mengarah pada resolusi refluks yang cepat. Kandung kemih neurogenik dengan peningkatan tekanan detrusor $(>40 \mathrm{~cm}$
$\mathrm{H} 2 \mathrm{O}$ ) harus diobati dengan kombinasi terapi medis (obat antikolinergik), kateterisasi, dan pembedahan, jika perlu. ${ }^{2}$

Pada kasus megaureter obstruksi, keputusan untuk pembedahan membutuhkan pertimbangan karena tingkat komplikasi yang lebih tinggi. Tidak ada pembedahan yang harus dilakukan selama fungsi ginjal tidak terpengaruh secara signifikan dan infeksi saluran kemih bukan merupakan masalah utama. Antibiotik merupakan terapi awal yang diperlukan. Biasanya, pembedahan diperlukan antara usia satu dan dua tahun jika kondisinya memburuk. ${ }^{2}$

Dalam kasus-kasus tertentu yang jarang terjadi, intervensi dini diperlukan. Untuk mencegah komplikasi yang berkaitan dengan kejadian non-refluks, operasi re-implant pada bayi, opsi bedah lainnya harus dipertimbangkan, seperti loop ureterostomy, refluxing reimplant, dan bahkan pemasangan stent ureter. $^{8}$

\section{SIMPULAN}

Gambaran ground glass appearance pada foto polos dapat menyerupai hidronefrosis atau masa ginekologi terutama pada wanita muda yang dicurigai massa abdomen.

\section{KONFLIK KEPENTINGAN}

Penulis menyatakan bahwa tidak terdapat konflik kepentingan dalam penulisan artikel ini.

\section{PENDANAAN}

Penulis bertanggung jawab secara mandiri dalam pendanaan laporan kasus ini tanpa melibatkan pihak sponsor atau sumber pendanaan lainnya.

\section{KONTRIBUSI PENULIS}

RM dan NNM berperan dalam penyusunan laporan kasus, pemeriksaan pasien, maupun follow-up pemeriksaan terhadap pasien.

\section{DAFTAR PUSTAKA}

1. Paonam S, Bag S. Congenital segmental giant megaureter presenting as cystic abdominal mass in a child. J Clin Case Rep. 2015;5(10):614.

2. Hodges SJ, Werle D, McLorie G, Atala A. Megaureter. ScientificWorldJournal. 2010;10:603-612.

3. Lee BR, Silver RI, Partin AW, Epstein JI, Gearhart JP. A quantitative histologic analysis of collagen subtypes: the primary obstructed and refluxing megaureter of childhood. Urology. 1998;51:820-823.

4. Berrocal T, Lopez-Pereira P, Arjonilla A, Gutierrez J. Anomalies of the distal ureter, bladder, and urethra in children: embryologic, radiologic, and pathologic features. Radiographics. 2002;22:1139-1164. 
5. Sindhughosa DA, Pranamartha AAGMK. The involvement of proinflammatory cytokines in diabetic nephropathy: Focus on interleukin 1 (IL-1), interleukin 6 (IL-6), and tumor necrosis factor-alpha (TNF- $\alpha$ ) signaling mechanism. Bali Medical Journal. 201;6(1):44-51.

6. Saurabh G, Lahoti BK, Geetika P. Giant megaureter presenting as cystic abdominal mass. Saudi J Kidney Dis Transpl. 2010;21:160-162.

7. Yu M, Ma G, Ge Z, Lu R, Deng Y, Guo Y. Unilateral congenital giant megaureter with renal dysplasia compressing contralateral ureter and causing bilateral hydronephrosis: a case report and literature review. BMC Urol. 2016;16:7
8. Khoury A, Bagli D. Reflux and megaureter. Dalam: Partin AW, Peters CA, Kavoussi LR, Dmochowski RR, Wein AJ, penyunting. Campbell Walsh Wein Urology. Edisi ke-9. Canada: Elsevier; 2007.

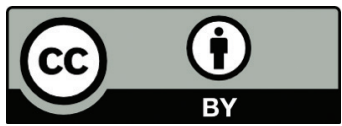

This work is licensed under a Creative Commons Attribution 